\title{
Furin-dependent CCL17-fused recombinant toxin controls HTLV-1 infection by targeting and eliminating infected CCR4-expressing cells in vitro and in vivo
}

\author{
Masateru Hiyoshi ${ }^{1 \dagger}$, Kazu Okuma ${ }^{1 *}$, Seiji Tateyama ${ }^{1,2}$, Kazuya Takizawa' ${ }^{1}$, Masumichi Saito ${ }^{1}$, Madoka Kuramitsu', \\ Kumiko Araki ${ }^{1}$, Kazuhiro Morishita ${ }^{3}$, Seiji Okada ${ }^{4}$, Naoki Yamamoto ${ }^{5}$, Arya Biragynn ${ }^{6}$, Kazunari Yamaguchi ${ }^{1}$ \\ and Isao Hamaguchi ${ }^{*}$
}

\begin{abstract}
Background: Adult T-cell leukemia (ATL) is caused by human T-cell leukemia virus type 1 (HTLV-1) infection. However, there are no therapies to prevent ATL development in high-risk asymptomatic carriers. To develop a therapy targeting HTLV-1-infected cells that are known to express CCR4 frequently, we tested whether truncated Pseudomonas exotoxin (PE38) fused to a CCR4 ligand, CCL17/thymus and activation-regulated chemokine (TARC), selectively eliminates such cells.

Results: Our data show that TARC-PE38 efficiently killed HTLV-1-infected cell lines. It also shrank HTLV-1-associated solid tumors in an infected-cell-engrafted mouse model. In HTLV-1-positive humanized mice, TARC-PE38 markedly inhibited the proliferation of HTLV-1-infected human $\mathrm{CD}_{4}^{+} \mathrm{CD} 25^{+}$or $\mathrm{CD}^{+}{ }^{+} \mathrm{CD} 25^{+} \mathrm{CCR} 4^{+}$cells and reduced the proviral loads (PVLs) in peripheral blood mononuclear cells (PBMCs). Importantly, TARC-PE38 significantly reduced the PVLs in PBMCs obtained from asymptomatic carriers. We show that the cytotoxicity of TARC-PE38 is mediated by the expression of the proprotein convertase, furin. The expression of furin was enhanced in HTLV-1-infected cells and correlated positively with PVLs in HTLV-1-infected individuals, suggesting that infected cells are more susceptible to TARC-PE38 than normal cells.
\end{abstract}

Conclusions: TARC-PE38 robustly controls HTLV-1 infection by eliminating infected cells in both a CCR4- and furindependent manner, indicating the excellent therapeutic potential of TARC-PE38.

Keywords: HTLV-1, CCR4, CCL17/TARC, Pseudomonas exotoxin, Furin

\section{Background}

Human T-cell leukemia virus type 1 (HTLV-1) is a human retrovirus that causes HTLV-1-related diseases, including adult T-cell leukemia (ATL) [1-5]. ATL develops in asymptomatic carriers of HTLV-1 after latent infection for at least $20-30$ years, with an estimated lifetime risk

*Correspondence: kokuma@niid.go.jp; 130hama@niid.go.jp

${ }^{\dagger}$ Masateru Hiyoshi and Kazu Okuma contributed equally to this study

${ }^{1}$ Department of Safety Research on Blood and Biological Products,

National Institute of Infectious Diseases, Musashimurayama, Tokyo

208-0011, Japan

Full list of author information is available at the end of the article of $6-7 \%$ for males and $2-3 \%$ for females [6]. A recent national survey in Japan reported at least one million eighty thousand asymptomatic carriers [7]. Although several anti-ATL therapies are available, including chemotherapy $[8,9]$, ATL is often resistant to these and its prognosis remains poor $[10,11]$. The Joint Study on Predisposing Factors of ATL Development (JSPFAD) [12] showed that asymptomatic carriers with a proviral load (PVL) exceeding $4 \%$ (copies/100 cells) constitute a high-risk group in whom ATL selectively develops [13]. Therefore, active interventions, including a prophylactic 
therapy, are urgently required to prevent the progression to ATL in this high-risk group.

Thymus and activation-regulated chemokine (TARC)/ CCL17 and macrophage-derived chemokine (MDC)/ CCL22 share CC chemokine receptor 4 (CCR4), which is predominantly expressed on type 2 helper $\mathrm{T}$ cells and regulatory $\mathrm{T}$ cells (Tregs) [14-17]. Recent studies have demonstrated that CCR4 is frequently expressed in HTLV-1-infected cells, which are predominantly $\mathrm{CD} 4{ }^{+} \mathrm{CD} 25^{+}[18-21]$. The expression of MDC is also induced by the HTLV-1 transactivator protein, Tax, in infected cells [22]. The induced MDC seems to attract normal CCR $4^{+}$T-cells, resulting in the preferential infection of these cells [22] via cell-to-cell contact [23], and maintain a high frequency of functional $\mathrm{CCR} 4^{+} \mathrm{FoxP}^{+}$ Tregs [24].

Recently, a defucosylated humanized anti-CCR4 monoclonal antibody (mAb), mogamulizumab, was developed as an anti-ATL drug [25-30]. This drug specifically binds to CCR4 on ATL cells and exerts antibody-dependent cellular cytotoxicity (ADCC) against the cells by binding to the Fc receptor $(\mathrm{FcR})$ on NK cells. However, although this therapy is effective [30], severe adverse events have been reported [31-33].

In this study, we developed a candidate anti-HTLV-1 therapeutic agent targeting CCR4, with a mode of action that differs from that of mogamulizumab. Our novel agent is TARC-fused truncated $38-\mathrm{kDa}$ Pseudomonas aeruginosa exotoxin $\mathrm{A}$ (PE38) in which the CD91-binding domain is deleted, designated TARC-PE38 [34]. Full-length PE is known to elicit a cytotoxic effect that is dependent on the intracellular expression of the proprotein convertase, furin $[35,36]$, when it moves into cells by endocytosis after specifically binding to CD91 on the cell surface via its CD91-binding domain [37, 38]. However, when the CD91-binding domain of PE is switched for another protein-binding domain, the chimeric protein shows a new targeting specificity, dependent on the properties of the switched protein. Thus, TARC-PE38 is expected to specifically bind to CCR4 on target cells via its TARC domain and to exert similar cytotoxic effects on $\mathrm{CCR}_{4}^{+}$cells alone, in a furin-dependent manner. This therapeutic effect on HTLV-1-infected CCR4 ${ }^{+}$cells was tested in vitro and in vivo to determine the drug potential of TARC-PE38 in reducing the risk of ATL development in high-risk asymptomatic carriers.

\section{Results}

Elimination of HTLV-1-infected CCR4 ${ }^{+}$cells by TARC-PE38

Our previous study showed that TARC-PE38 effectively killed HTLV-1-negative CCR4-expressing T cells, CCRF$\mathrm{CEM}$, through the apoptosis in vitro and eliminated tumors using this cell line in model mice (in vivo) by the injections subcutaneously and intravenously [34].

In this study, HTLV-1-infected S1T, TL-Om1, MT-2, and HUT-102 cells were tested to examine the effect of TARC-PE38 on them. These cells were first analyzed with flow cytometry to confirm their cell-surface expression of CCR4 (Fig. 1a). As controls, HTLV-1-uninfected Jurkat, Raji, U937, and THP-1 cells were examined in parallel. As expected, the S1T, TL-Om1, MT-2, and HUT-102 cells expressed CCR4 with the mean fluorescence intensity (MFI) of 332.9, 49.6, 197.7, and 27.8, respectively. The Jurkat cells expressed CCR4 at a lower level (MFI: 26.8) and the Raji, U937, and THP-1 cells expressed no CCR4.

Therefore, we tested the killing effect of TARC-PE38 (10 or $20 \mu \mathrm{g} / \mathrm{ml}$ ) on these cells (Fig. 1b). The TARC-fused oncofetal antigen (TARC-OFA; 10 or $20 \mu \mathrm{g} / \mathrm{ml}$ ) and phosphate-buffered saline (PBS) were used as controls. Whereas TARC-OFA and PBS did not kill any of the cells tested, TARC-PE38 killed the S1T, TL-Om1, MT-2, and HUT-102 cells efficiently, and the Jurkat cells much less effectively. TARC-PE38 killed no Raji, U937, and THP-1 cells, consistent with their lack of CCR4 expression.

We also examined whether either TARC-PE38 or TARC-OFA (control) killed the same cells in a dosedependent manner $(0-20 \mu \mathrm{g} / \mathrm{ml})$ (Fig. 1c). Surprisingly, TARC-PE38 killed the S1T cells completely, even at the lowest dose $(5 \mu \mathrm{g} / \mathrm{ml})$, probably because they have the highest cell-surface expression (MFI) of CCR4. TARCPE38 killed the TL-Om1, MT-2, and HUT-102 cells in a dose-dependent manner. However, even when the dose was increased to $20 \mu \mathrm{g} / \mathrm{ml}$, the killing effect of TARCPE38 was only modestly enhanced in the Jurkat cells and not at all in the Raji, U937, and THP-1 cells. TARC-OFA killed none of the cells at any dose tested.

As demonstrated by flow cytometry, the HUT-102 cells expressed CCR4 at a similar MFI to the Jurkat cells (27.8 vs 26.8 , respectively), but most whole HUT-102 cells expressed CCR4 like the TL-Om1 cells (almost $100 \%$ positive) and unlike the Jurkat cells (lower \% positive) (Fig. 1a). Thus, when TARC-PE38 was added to the HUT-102 cells, TARC-PE38 killed the cells more effectively than it killed the Jurkat cells (Fig. 1b, c).

In addition, to rule out nonspecific effects of PE38, we examined whether PE38 alone (no protein fused to PE38) killed CCR4 ${ }^{+}$S1T cells in parallel with PBS. PE38 alone $(20 \mu \mathrm{g} / \mathrm{ml})$ as well as PBS did not kill the S1T cells at all (Fig. 1d). Thus, as neither TARC-OFA, PBS, nor PE-38 alone killed any cells tested, PBS alone was used as a negative control in the following experiments.

Therefore, TARC-PE38 targets CCR4 ${ }^{+}$cells and exerts a cytotoxic effect on HTLV-1-infected cells in vitro, at least in a CCR4-expression-dependent manner. 

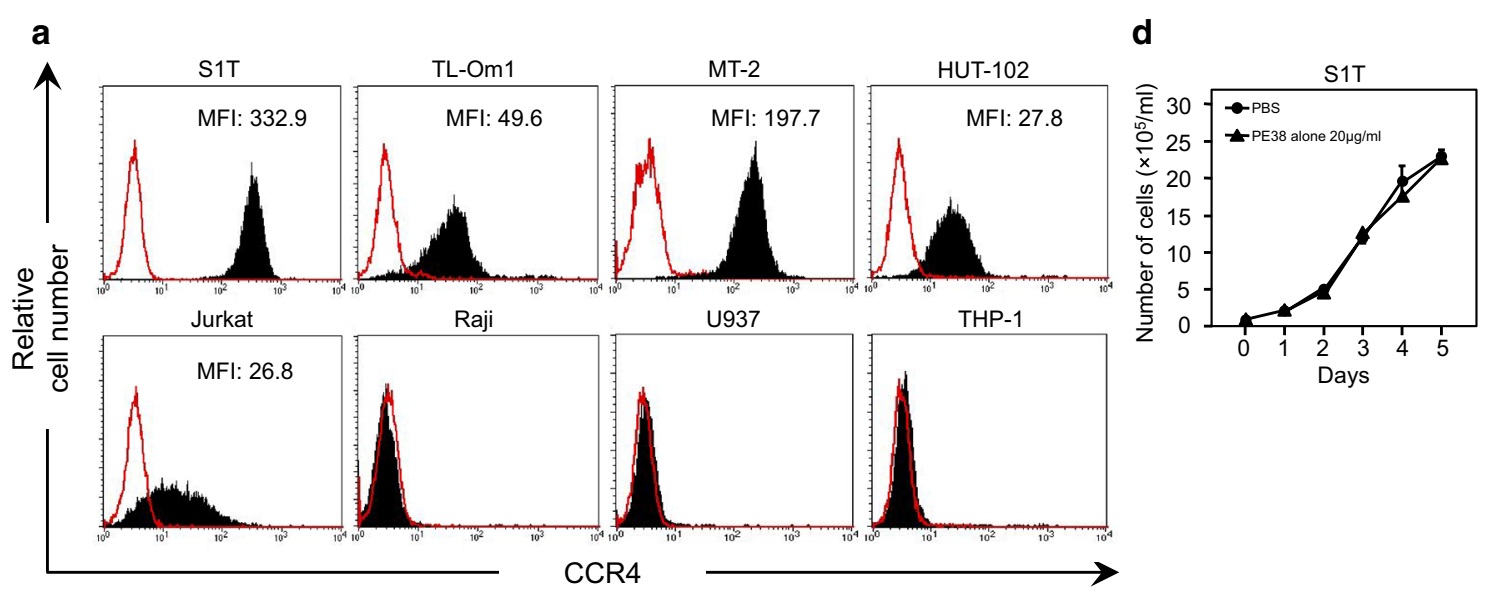

b
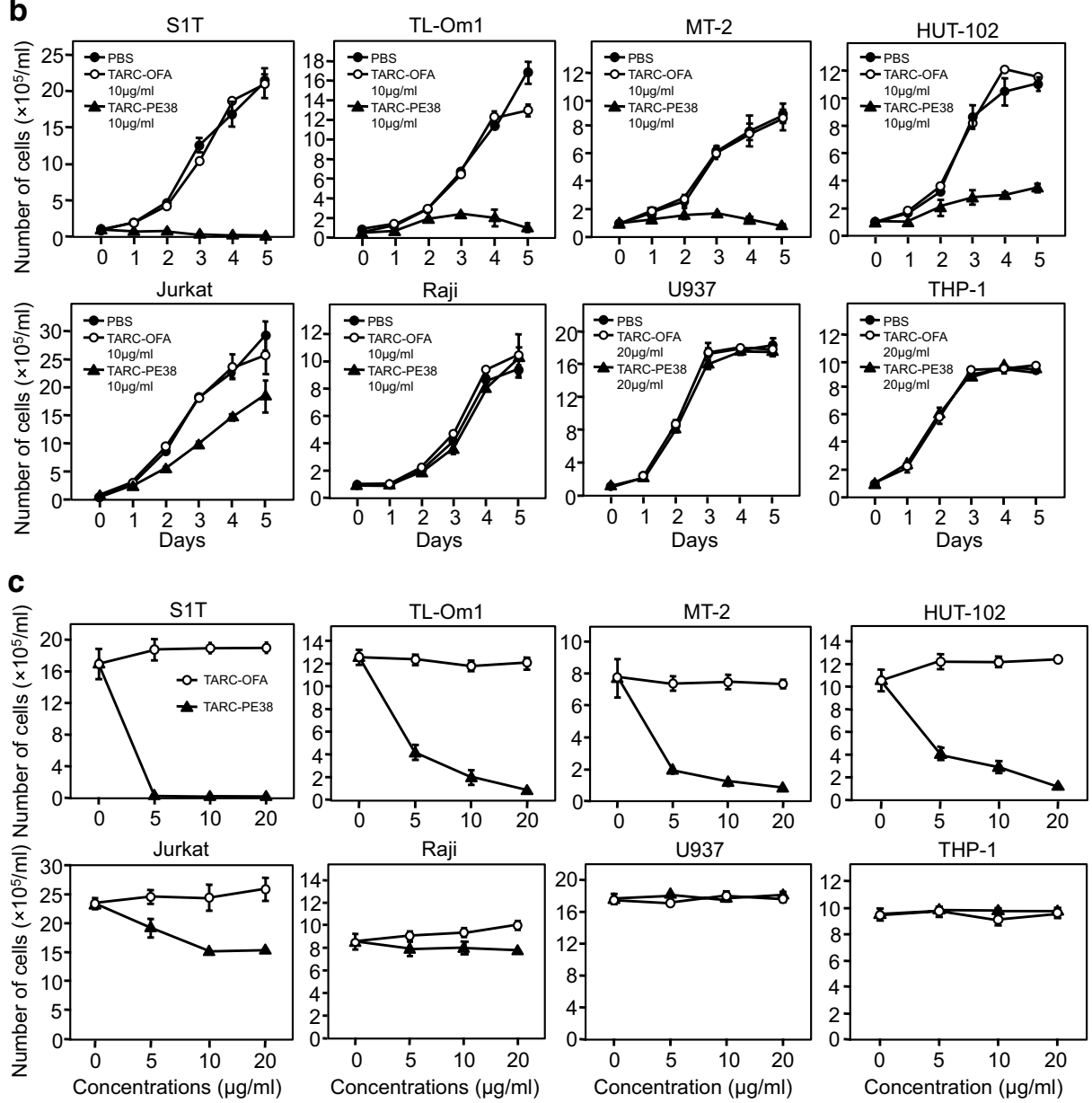

Fig. 1 Elimination of HTLV-1-infected cell lines by TARC-PE38. a HTLV-1-infected S1T, TL-Om1, MT-2, and HUT-102 cells and uninfected Jurkat, Raji, U937, and THP-1 cells were tested for their expression of CCR4 with flow cytometry without (solid red line) or with an anti-CCR4 antibody (solid line filled with black). MFI, mean fluorescence intensity. $\mathbf{b}$ To examine the killing effects of TARC-PE38 on the cells described above, the numbers of live cells were counted daily for 5 days after either 10 or $20 \mu \mathrm{g} / \mathrm{ml}$ TARC-PE38 (closed triangles), 10 or $20 \mu \mathrm{g} / \mathrm{ml}$ TARC-OFA (open circles), or PBS (closed circles) was added to each cell line. The data are expressed as means \pm SD $\left(\times 10^{5} / \mathrm{ml}\right)$. c To further determine the cytotoxicity of TARC-PE38 in the cells described above, each cell line was incubated with either TARC-PE38 (closed triangles) or TARC-OFA (open circles) at doses of 0 (PBS only added), 5, 10, or $20 \mu \mathrm{g} / \mathrm{ml}$ for 5 days, and the numbers of live cells were then counted. The data are expressed as means $\pm S D\left(\times 10^{5} / \mathrm{ml}\right)$. d To rule out nonspecific effects of PE38, either PBS (closed circles) or $20 \mu \mathrm{g} / \mathrm{ml} \mathrm{PE38}$ alone (closed triangles) was added to S1T cells. Then the numbers of live cells were counted daily for 5 days, and the data are expressed as means $\pm S D\left(\times 10^{5} / \mathrm{ml}\right)$. These results are representative of four independent experiments 


\section{Regressive effect of TARC-PE38 on HTLV-1-associated tumor in a mouse model}

Next, to examine the in vivo effects of TARC-PE38, we constructed an HTLV-1-associated tumor-bearing mouse model. Because HTLV-1-infected HUT-102 cells are known to form tumors in immunodeficient mice most efficiently among cells tested [39], this cell line was selected to generate this model.

In a tumor-bearing mouse model with the HUT-102 cells, TARC-PE38 had a striking regressive effect on the mass of the solid tumors in five mice treated with TARC-PE38 compared with five mice treated with PBS (Fig. 2a, b). The weights of the tumors were more strongly reduced by treatment with TARC-PE38 (mean final weight $\sim 0.1 \mathrm{~g}$ ) than by treatment with PBS (mean final weight $\sim 0.6 \mathrm{~g}$ ), and the difference in weight between the groups was statistically significant $(\mathrm{p}<0.0001$; Fig. $2 \mathrm{c})$.

Therefore, TARC-PE38 efficiently inhibits tumor growth in an HTLV-1-associated tumor-bearing mouse model.

\section{Therapeutic effect of TARC-PE38 on HTLV-1 infection in humanized mice}

To further confirm the in vivo efficacy of TARC-PE38 against HTLV-1, we constructed six HTLV-1-infected and three uninfected, humanized mice. Fourteen days after infection with mitomycin C (MMC)-treated MT-2 cells, we used flow cytometry and quantitative PCR to confirm that no residual MT-2 cells were present in the infected mice (Additional file 1: Figure S1, Additional file 2: Figure S2, Additional file 3: Table S1). As shown in Fig. 3a, either $10 \mu \mathrm{g}$ of TARC-PE38 per mouse or PBS (control) was administered to three of the six infected mice once a day on days 14-17. All the mice were bled on days $0,14,21,28$, and later, and peripheral blood mononuclear cells (PBMCs) were then isolated from the blood.

Using flow cytometry, we tested the frequency of human HTLV-1-infected $\mathrm{CD} 4{ }^{+} \mathrm{CD} 25^{+}$cells in human $\mathrm{CD} 45^{+}$cells of the PBMCs (Fig. 3b, c). Because binding of TARC to CCR4 on cells induces internalization (downregulation) of CCR4 via endocytosis of a TARC-CCR4 a

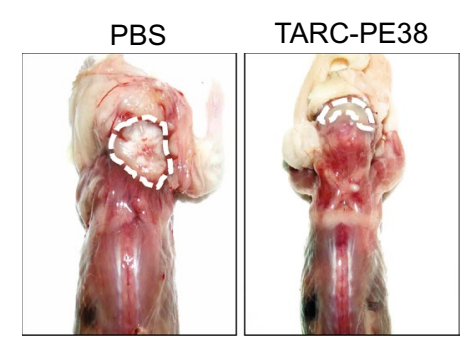

C

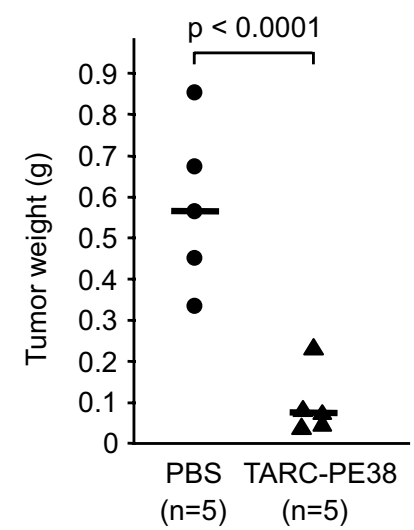

b

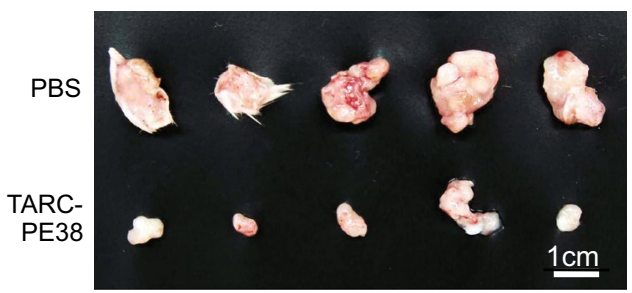

Fig. 2 Antitumor effect of TARC-PE38 in a mouse model bearing an HTLV-1-related tumor. a HUT-102 cells ( $2 \times 10^{7}$ cells/mouse) were transplanted into the postauricular regions of 10 NOG mice. Either $25 \mu \mathrm{g} /$ mouse TARC-PE38 or PBS was then administered to the same region once a day on days 1-5 after transplantation (a total of five times). The mice were observed and sacrificed on day 14 after transplantation to assess the therapeutic effect of TARC-PE38 on the solid tumors grown in the same region. The sizes of the tumors were compared among the mice sacrificed. Representative tumors of mice treated with PBS or TARC-PE38 were photographed with a standard digital camera. The tumors are surrounded by wavy lines. b All tumors grown in mice treated with PBS ( $n=5$, upper line) or TARC-PE38 ( $n=5$, lower line) were excised from the mice, compared, and photographed in the same way. The white bar represents $1 \mathrm{~cm}$. c Tumors excised from mice treated with PBS $(n=5$, closed circles) or TARC-PE38 $(n=5$, closed triangles) were all weighed (in grams, $g$ ), and compared statistically $(p<0.0001)$. Bar represents the mean. These data are representative of more than two independent experiments 
a

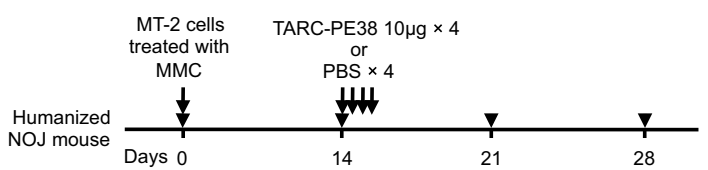

b

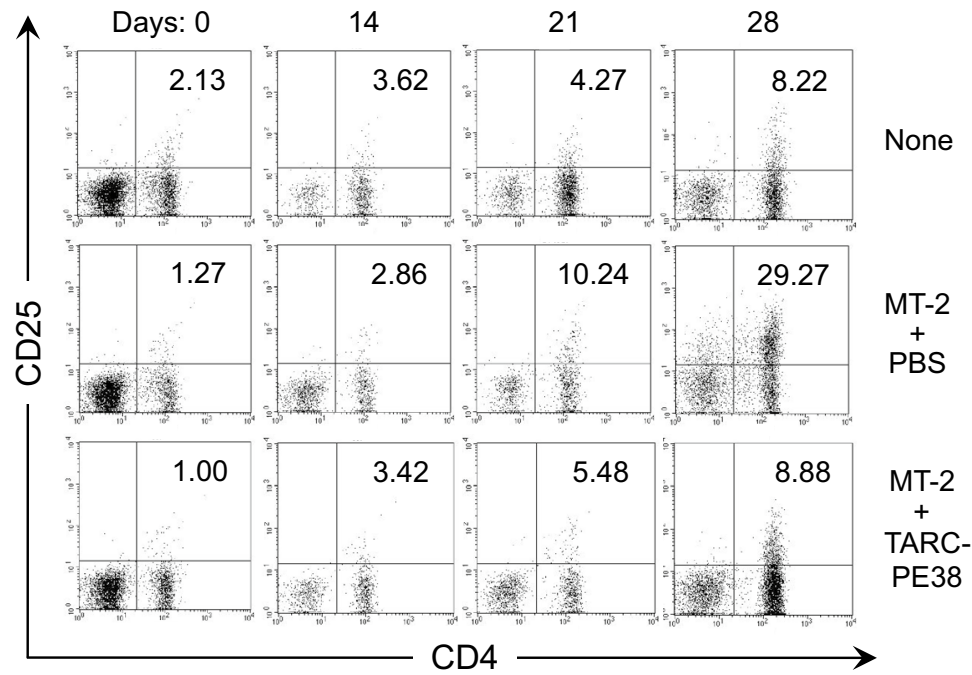

C

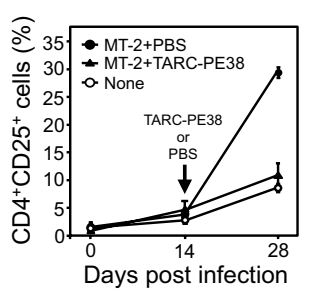

d

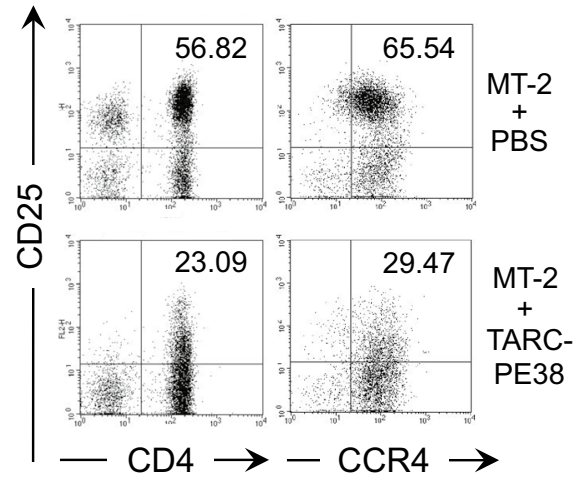

e

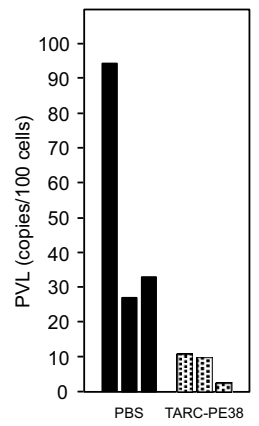

Fig. 3 Antiviral effect of TARC-PE38 on HTLV-1 infection in humanized mice. a CD34+ HSCs were purified from human cord blood and transplanted intrahepatically into newly born NOJ mice. After these mice were humanized, nine mice were inoculated intraperitoneally without ( $n=3$, PBS only) or with MT-2 cells treated with MMC $(n=6)$ (day 0). Two weeks later, either $10 \mu \mathrm{g}$ of TARC-PE38 or PBS was administered to the HTLV-1-infected mice (three mice in each group) intravenously once a day for four successive days (days 14-17). All mice were observed for more than 2 weeks after the administration of TARC-PE38 or PBS, and bled on days $0,14,21,28$, and later. $\mathbf{b}$ To assess the therapeutic effect of TARC-PE38 on HTLV-1-infected cells, peripheral blood was obtained from all the mice described above. The PBMCs were isolated and the frequency of human $C D 4^{+} \mathrm{CD} 25^{+}$ cells was determined with flow cytometry. The data are representative of each group as follows: none, uninfected untreated mice; MT-2 + PBS, HTLV-1-infected mice treated with PBS; MT-2 + TARC-PE38, HTLV-1-infected mice treated with TARC-PE38. The number indicated in the upper right quadrant is the frequency of human $\mathrm{CD} 4{ }^{+} \mathrm{CD} 25^{+}$cells (\%). c The frequencies of human $\mathrm{CD} 4{ }^{+} \mathrm{CD} 25^{+}$cells $(\%)$ on the indicated days after infection are plotted for each mouse group: none (open circles), MT-2 + PBS (closed circles), or MT-2 + TARC-PE38 (closed triangles). The data are expressed as means $\pm \mathrm{SD}$ (\%). d To determine the effect of TARC-PE38 on $\mathrm{CD} 44^{+} \mathrm{CD} 25^{+}$or $\mathrm{CD} 4^{+} \mathrm{CD} 25^{+} \mathrm{CCR} 4^{+}$cells, PBMCs obtained from each mouse group (MT-2 + PBS or MT-2 + TARC-PE38) after day 28 were checked for the frequency of human $\mathrm{CD} 4^{+} \mathrm{CD} 25^{+}$cells (left panels) or $\mathrm{CD} 4^{+} \mathrm{CD} 25^{+} \mathrm{CCR} 4^{+}$cells (right panels) by flow cytometry. The number indicated in the upper right quadrant is the frequency of human $\mathrm{CD} 4^{+} \mathrm{CD} 25^{+}$or $\mathrm{CD} 4^{+} \mathrm{CD} 25^{+} \mathrm{CCR} 4^{+}$ cells (\%). e PBMCs obtained on day 28 from MT-2-infected mice treated with PBS (black bar) or with TARC-PE38 (dotted bar) were also used to measure PVLs with quantitative PCR. The data are presented as copies/100 cells. These results are representative of two independent experiments 
complex [34, 40], reduction of CCR4 ${ }^{+}$cells by treatment with TARC-PE38 reflects disappearance of CCR4 but may not exactly reflect elimination of $\mathrm{CCR}^{+}$cells (the killing effect of TARC-PE38 on CCR4 ${ }^{+}$cells). Therefore, to evaluate the killing effect of TARC-PE38 on infected $\left(\mathrm{CD} 4{ }^{+} \mathrm{CD} 25^{+} \mathrm{CCR} 4^{+}\right)$cells accurately, we checked $\mathrm{CD} 4{ }^{+} \mathrm{CD} 25^{+}$cells rather than $\mathrm{CCR} 4^{+}$cells. In the MT2-infected mice treated with TARC-PE38, the increase in the frequency of HTLV-1-infected cells was markedly inhibited compared with that in the MT-2-infected mice treated with PBS (mean 5.48 vs $10.24 \%$, respectively, on day 21 , and 8.88 vs $29.27 \%$, respectively, on day 28 ) and almost the same as that in the uninfected mice $(8.22 \%$ on day 28).

However, because in spite of TARC-induced internalization of CCR4, TARC-PE38 undergoes degradation after administration to mice in the humanized mouse model, the internalization of CCR4 is presumably not persistent during the long observation in vivo. Thus, data for $\mathrm{CCR} 4^{+}$cells in the humanized mouse model could be still important and supportive to evaluate the therapeutic effect of TARC-PE38, and indicated significant CCR4 ${ }^{+}$ cell reduction by treatment with TARC-PE38 (Additional file 4: Figure S3). It was also demonstrated after day 28 that a population of $\mathrm{CD} 4{ }^{+} \mathrm{CD} 25^{+}$cells (Fig. $3 \mathrm{~d}$, left panels) or $\mathrm{CD} 4^{+} \mathrm{CD} 25^{+} \mathrm{CCR} 4^{+}$cells (Fig. $3 \mathrm{~d}$, right panels) completely disappeared by treatment with TARC-PE38, indicating that the treatment selectively targets $\mathrm{CD} 25^{+}$ (infected) cells, not $\mathrm{CD}^{-} 5^{-}$(uninfected) cells, especially among CCR4 ${ }^{+}$cells.

We also measured the PVLs with quantitative PCR in PBMCs collected on day 28 from each mouse treated with TARC-PE38 or PBS. Consistent with the above results, the PVLs $(<10$ copies/100 cells) in the PBMCs from mice treated with TARC-PE38 were significantly lower than those (around 30-90 copies/100 cells) in mice treated with PBS (Fig. 3e).

Thus, TARC-PE38 exerts a potent therapeutic effect on HTLV-1 infection in a humanized mouse model.

\section{TARC-PE38 reduces PVLs in PBMCs from asymptomatic carriers}

We also examined the therapeutic effect of TARC-PE38 on primary HTLV-1-infected cells. Because in this study we mainly focused on the therapeutic potential of TARCPE38 to prevent the development of ATL for high-risk asymptomatic HTLV-1 carriers, not for ATL patients, we used PBMCs obtained from asymptomatic carriers alone in this experiment.

PBMCs obtained from seven asymptomatic carriers were incubated with 0 (PBS), 10, or $20 \mu \mathrm{g} / \mathrm{ml} \mathrm{TARC-}$ PE38 in the presence of interleukin 2 (IL2) for 5 days. The genomic DNA of the harvested PBMCs was then purified and used to measure the PVLs with quantitative PCR. Because of TARC-induced internalization of CCR4, reduction of $\mathrm{CCR}^{+}$cells by treatment with TARCPE38 may not exactly reflect elimination of $\mathrm{CCR} 4^{+}$cells (the killing effect of TARC-PE38 on CCR4 ${ }^{+}$cells) again. We therefore checked PVLs rather than CCR4 ${ }^{+}$cells to evaluate the killing effect of TARC-PE38 on infected cells accurately. As shown in Fig. 4, the PVLs all increased after the incubation as compared to those before the incubation. However, the PVLs in five of seven carriers tested definitely decreased after incubation with TARCPE38 compared with those after incubation with PBS, probably by killing HTLV-1-infected primary cells. This indicated that TARC-PE38 can effectively reduce the PVLs increasing during the active viral production.

\section{Furin-dependent cytotoxic effect of TARC-PE38 on HTLV-1-infected cells}

Because TARC-PE38 targets CCR4, it can attack normal CCR4 ${ }^{+}$cells. Thus, we compared a gene expression involved in the susceptibility to TARC-PE38 between HTLV-1-infected and uninfected CCR4 ${ }^{+}$cells.

Because full-length PE is cleaved within cells by the proprotein convertase, furin, which mediates its cytotoxicity $[35,36]$, we investigated the expression of furin. If there were a difference in the intracellular expression of furin by HTLV-1-infected and uninfected CCR4 ${ }^{+}$cells, it may affect the killing effect of TARC-PE38 on these cells.

To examine whether the cytotoxic activity of TARCPE38 is mediated by the expression of furin, we tested whether a furin inhibitor blocked the killing effect of TARC-PE38 in the S1T cells. Whereas the cells incubated with TARC-PE38 alone were killed expectedly, the cells incubated with both TARC-PE38 and the furin inhibitor grew well, at a similar rate to cells incubated with the furin inhibitor alone (Fig. 5a). Therefore, the furin inhibitor definitely blocked the effect of TARC-PE38, even in the S1T cells which are most susceptible to TARC-PE38 of all the cells tested (as shown in Fig. 1b, c), confirming that the effect of TARC-PE38 is furin-dependent.

Therefore, we quantified the expression of furin mRNA with quantitative RT-PCR in HTLV-1-infected S1T, TL-Om1, HUT-102, and MT-2 cells and in uninfected Jurkat cells, all CCR4 ${ }^{+}$cells (shown in Fig. 1a). The relative expression levels in the S1T, HUT-102, and MT-2 cells were around four-, two-, and six-fold higher, respectively, than that in the Jurkat cells, whereas that in the TL-Om1 cells was almost the same (Fig. 5b). These data indicated that most HTLV-1-infected cells express higher levels of furin than uninfected cells.

Regardless of the similar expression of the furin in TL-Om 1 and Jurkat cells, TL-Om 1 cells were clearly more susceptible to TARC-PE38 than Jurkat cells 


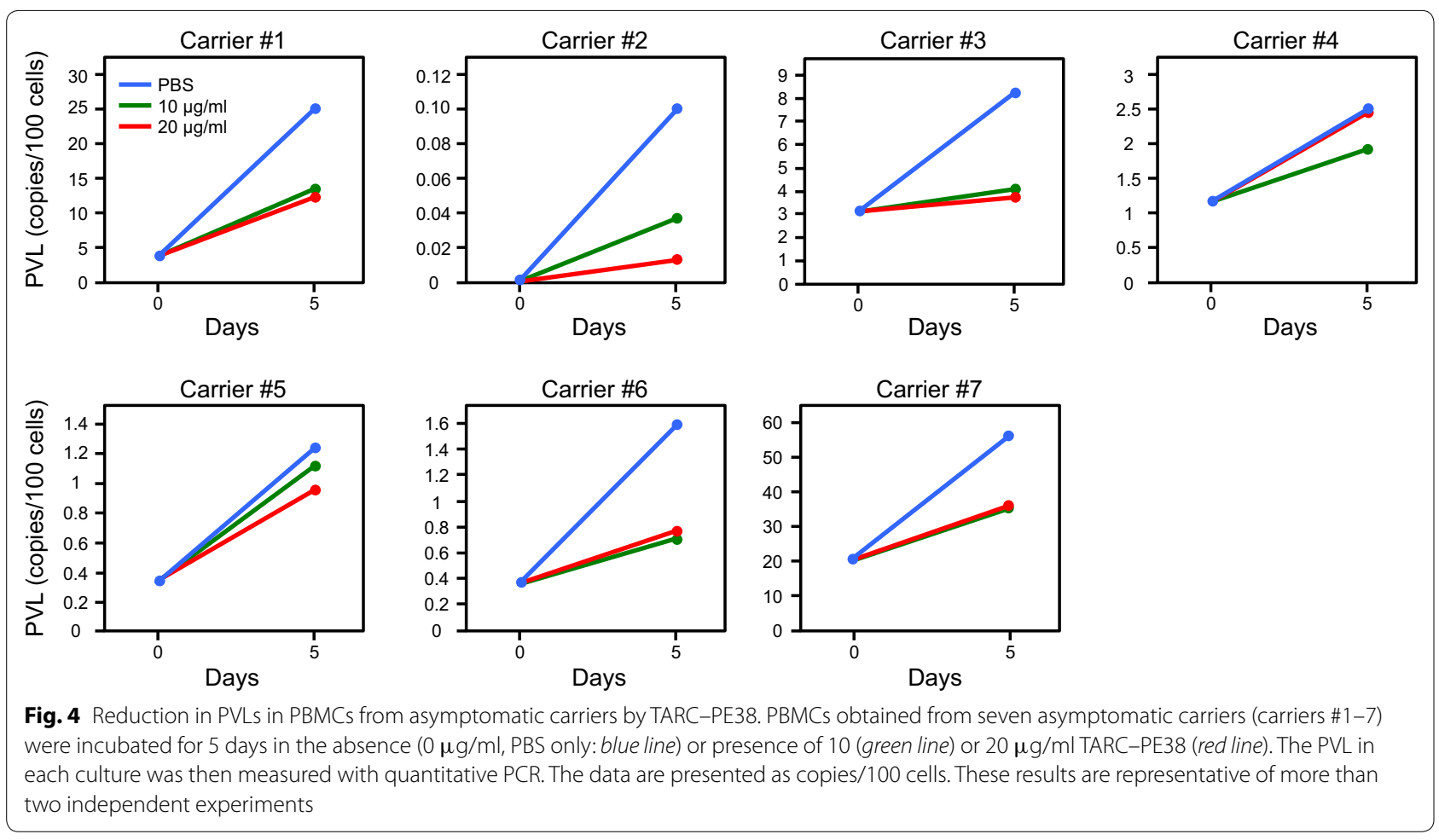

(shown in Fig. 1b, c). This suggests that when the furin is expressed similarly, the susceptibility to TARC-PE38 relies on the expression levels of CCR4 alone, as in fact those of CCR4 (MFI and/or percentage positive cells) were definitely higher in TL-Om1 cells than in Jurkat cells (shown in Fig. 1a).

\section{Intracellular furin expression is increased by HTLV-1 infection/production}

We then sought to clarify whether the intracellular expression of furin is enhanced by HTLV-1 infection. We compared two CCR4 ${ }^{+}$Jurkat-based cell lines, uninfected parental JET35 cells and HTLV-1-infected JEX22 cells which produce HTLV-1 upon stimulation with phorbol 12-myristate 13-acetate (PMA)/ionomycin and express tdTomato (around $27 \%$ positive when analyzed with flow cytometry), dependent on Tax expression. In these cells, we determined the frequencies of tdTomato-positive cells and the expression levels of furin mRNA with flow cytometry and quantitative RT-PCR, respectively, before and after the cells were stimulated. A flow-cytometric analysis showed that the JET35 and JEX22 cells expressed almost no tdTomato before stimulation. The stimulated JET35 cells were tdTomato-negative, whereas $98.4 \%$ of the stimulated JEX22 cells were tdTomato-positive after sorting (Fig. 5c, upper panels). Quantitative RT-PCR showed the relative expression levels in each type of cell compared with that in Jurkat cells (Fig. 5c, lower panel).
Interestingly, before stimulation, the expression of furin in HTLV-1-nonproducing JEX22 cells was almost the same as that in the JET35 cells (0.93 vs 1 , respectively). However, after stimulation, the expression of furin in the HTLV-1-producing JEX22 cells (sorted above) was around two-fold higher than that in the JET35 cells (4.63 vs 2.5 , respectively). Also the expression of furin in the same stimulated JEX22 cells was around five-fold higher than that in the non-stimulated JET35 or JEX22 cells (4.63 vs 1 or 0.93 , respectively). These data demonstrated that HTLV-1 infection/production enhances the intracellular expression of furin.

To support this finding, we checked whether there was a positive correlation between PVLs and the expression of furin mRNA in PBMCs collected from 29 HTLV1-infected individuals (Additional file 5: Table S2). When PVLs and the expression of furin mRNA were measured in PBMCs with quantitative PCR and quantitative RTPCR, respectively, there was a clear positive correlation between them $(R=0.689, p<0.0001)$ (Fig. $5 d$ ).

These results strongly suggest that TARC-PE38 eliminates HTLV-1-infected CCR $4^{+}$cells more effectively than normal $\mathrm{CCR}^{+}{ }^{+}$cells in a furin-expression-dependent manner.

\section{Discussion}

Approximately $20-30 \%$ of asymptomatic carriers are in the high-risk group, with $>4 \%$ (copies/100 cells) PVL 
a

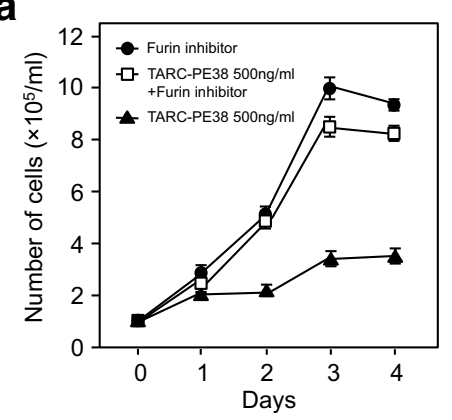

C
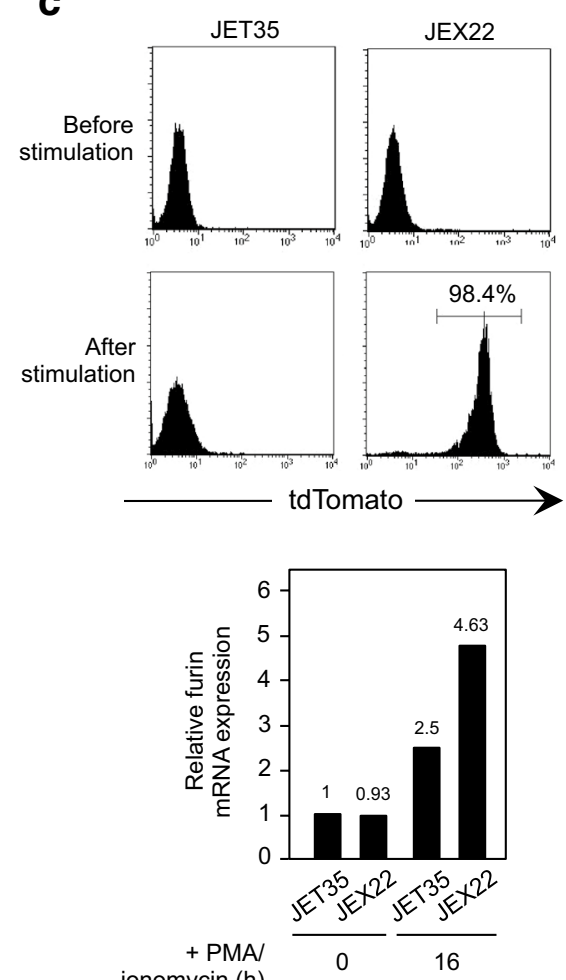

b

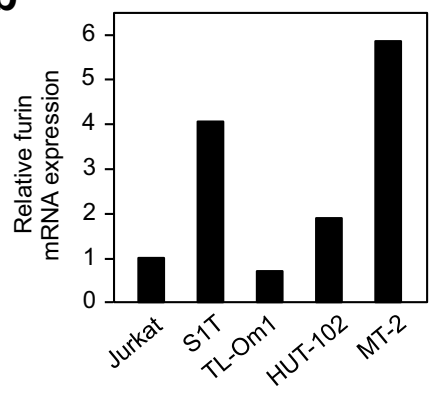

d

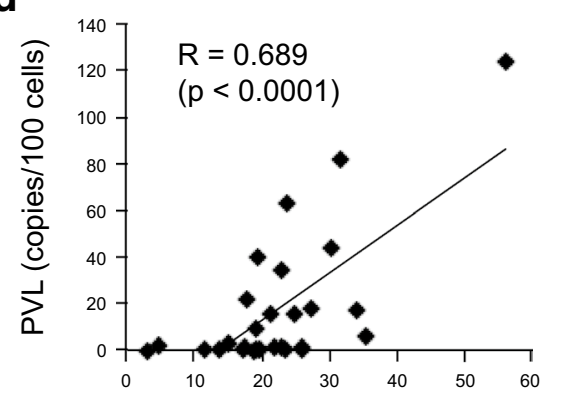

Relative furin mRNA expression

ionomycin (h)

Fig. 5 Furin-dependent activity of TARC-PE38 and increase in furin expression by HTLV-1 infection. a To test whether the effect of TARC-PE38 is dependent on furin expression, S1T cells were incubated with $500 \mathrm{ng} / \mathrm{ml}$ TARC-PE38 only (closed triangles), $500 \mathrm{ng} / \mathrm{ml}$ TARC-PE38 and a furin inhibitor (open squares), or the furin inhibitor only (closed circles) for 4 days. The numbers of live cells were counted daily to assess cell viability. The data are presented as means $\pm S D\left(\times 10^{5} / \mathrm{ml}\right)$. b Furin mRNA expression levels were measured with quantitative RT-PCR in HTLV-1-infected S1T, TL-Om1, HUT-102, and MT-2 cells and uninfected Jurkat cells. The data are presented as the expression level determined in each cell line relative to that in Jurkat cells. c The frequencies of tdTomato-positive cells in parental uninfected JET35 cells and HTLV-1-infected JEX22 cells before and $16 \mathrm{~h}$ after stimulation with PMA/ionomycin were analyzed with flow cytometry (upper panels) and the expression levels of furin were measured with quantitative RT-PCR (lower panel). The frequency in stimulated JEX22 cells is presented as a percentage (\%) and the expression level determined in each cell line is relative to that in Jurkat cells. As for the stimulated JEX22 cells, only tdTomato-positive HTLV-1-producing cells were isolated and used for the assays. d PBMCs obtained from 29 HTLV-1-infected individuals were used to examine the relationship between furin expression and PVLs. The furin mRNA expression levels and PVLs in these PBMCs were determined with quantitative RT-PCR and quantitative PCR, respectively. Each furin mRNA expression level is presented as the level determined in each sample relative to that in Jurkat cells. PVLs determined in the samples are presented as copies/100 cells. The correlation between the two parameters was then investigated statistically $(R=0.689, p<0.0001)$

in Japan [13]. To block the development of ATL in this group, the PVL must be controlled. Therefore, in this study, we focused on HTLV-1-infected CCR4 $4^{+}$cells carrying the provirus, to develop a new antiviral agent.
A defucosylated humanized anti-CCR4 mAb, mogamulizumab, was recently developed as a CCR4-targeting immunotherapy for ATL [25-30]. This study confirmed that a CCR4-targeting therapy against ATL cells is 
convincing and reliable. However, the anti-CCR4 mAb therapy induces several serious adverse effects, including Stevens-Johnson syndrome/toxic epidermal necrolysis, when normal CCR $4^{+}$Tregs are attacked [31-33].

As an "immunotoxin" (toxin fused to a ligand) [41-43] against ATL cells strongly expressing CD25 (IL2 receptor $\alpha$ chain), anti-Tac (Fv)-PE38/LMB-2, in which the Fv portion of an anti-CD25 antibody is fused to PE38, has been developed by other investigators [44, 45], but its therapeutic effect on ATL was limited [44]. Therefore, we developed TARC-PE38 targeting CCR4 as a novel candidate anti-HTLV-1 drug.

When we examined the therapeutic effect of TARCPE38 on primary HTLV-1-infected cells, responders (carriers \#1, 2, 3, 6, and 7) and non-responders (carriers \#4 and 5) to TARCPE38 could be clearly identified among the asymptomatic carriers. This difference in response to TARC-PE38 is probably, at least in part, due to the expression levels of CCR4 at the cell surface of PBMCs obtained.

TARC-PE38 has several major advantages. (1) Although the anti-CCR4 mAb functionally requires the ADCC activity mediated by NK cells, TARC-PE38 exerts a cytotoxic effect by itself, independent of ADCC activity. Therefore, TARC-PE38 can even be used in the absence of functional NK cells in immunocompromised hosts. (2) The anti-CCR4 mAb functions by binding to FcR on NK cells, but does not kill CCR4-expressing ATL cells uniformly in vitro, suggesting that the function of the antiCCR4 mAb may be affected by polymorphism of FcR [26]. In fact, FcR polymorphisms have been shown to impact the ADCC activity of other antibody-treatments $[46,47]$. However, since TARC-PE38 does not need to bind to FcR to function, the function of TARC-PE38 is not affected by FcR polymorphisms. (3) The anti-CCR4 $\mathrm{mAb}$ attacks normal CCR $4^{+}$cells in the same way as it attacks $\mathrm{CCR}^{+}{ }^{+}$ATL cells, whereas TARC-PE38 seems to attack HTLV-1-infected CCR4 ${ }^{+}$cells more effectively than it attacks normal $\mathrm{CCR}^{+}$cells. This advantage depends on the upregulation of furin expression in the infected cells, and may enhance the therapeutic effect additively/synergistically while reducing the severe adverse effects of the CCR4-targeting therapy.

The PE38 protein is immunogenic in the human body. Because of this immunogenicity there is a limitation in doses given and repeated administrations of PE38-fused proteins to patients with normal immune systems. However, it was recently reported that silencing of T-cell epitopes in PE38 could diminish its immunogenicity [48]. Such a modification of PE38 would be very helpful in clinical applications of TARC-PE38.
The expression of the proprotein convertase, furin, is essential for the maintenance of the peripheral immune tolerance mediated by Tregs [49]. It has recently been reported that HTLV-1 primarily infects Tregs in patients with HTLV-1-associated myelopathy/tropical spastic paraparesis (HAM/TSP) [21]. Therefore, HTLV-1 may take advantage of furin to enhance Treg functions by the preferential infection and expansion of Tregs. This idea is supported by the results of this study, which demonstrate both enhanced furin expression in HTLV-1-infected cells and a positive correlation between furin mRNA expression and PVLs in HTLV-1-infected individuals. However, the molecular mechanism underlying the increase in furin expression during HTLV-1 infection remains to be clarified. The expression of furin is not elevated by the induced expression of HTLV-1 Tax in JPX-9 cells [50] (Additional file 6: Figure S4).

A recent study has also shown that furin mRNA expression in the peripheral blood correlates with chronic hepatitis $B$ virus (HBV) infection, suggesting the participation of furin in Treg-mediated immune suppressive mechanisms during HBV infection [51]. This supports our finding that furin mRNA expression correlates with HTLV-1 infection. These observations during HTLV-1 and HBV infections may reflect a common survival strategy of viruses, through furin-mediated Treg function, to avoid the human immune response to viral infection. Because furin is probably involved in processing the HTLV-1 envelope glycoproteins [52], which play an important role in viral entry into host cells $[53,54]$, the enhanced expression of furin may also facilitate virus production.

\section{Conclusions}

In this study, we demonstrated the robust therapeutic effects of TARC-PE38 on HTLV-1 infection in vitro and in vivo. We also report that TARC-PE38 may function more efficiently against HTLV-1-infected cells than against normal cells through the proprotein-converting (toxin-cleavage) activity provided by the HTLV-1-induced increase in furin expression. Therefore, because the therapeutic effects of TARC-PE38 depend on the expression of both CCR4 and furin, the effects mediated by the expression of each of these proteins may be additive, synergistic, and/or compensative. Undoubtedly, the strong expression of these proteins in HTLV-1-infected cells should greatly enhance the efficacy of TARC-PE38. Collectively, our results indicate that TARC-PE38 is a useful and promising candidate therapeutic agent for controlling HTLV-1 infection, and therefore has significant prophylactic potential in preventing the development of ATL in the high-risk asymptomatic carriers of HTLV-1. 


\section{Methods \\ Cells}

The Jurkat and Raji cells are HTLV-1-negative human T-cell and B-cell lines, respectively. The U937 and THP-1 cells are HTLV-1-negative human monocytic cell lines. The S1T, TL-Om1, MT-2, and HUT-102 cells are HTLV1-infected human T-cell lines [55-58]. The JET35 cells are indicator Jurkat cells stably transfected with a plasmid encoding the tdTomato under the control of the Tax response element. The JEX22 cells are the JET35 cells infected with the HTLV-1 molecular clone pX1 MT-M [59]. When stimulated with $50 \mathrm{ng} / \mathrm{ml}$ PMA and $1 \mu \mathrm{M}$ ionomycin for $16-24 \mathrm{~h}$, The JEX22 cells produce HTLV-1 and simultaneously express tdTomato in response to the Tax expression.

Human peripheral blood obtained from HTLV-1-infected individuals including asymptomatic carriers was provided by JSPFAD. PBMCs were isolated from the blood with Ficoll-Histopaque (Sigma-Aldrich, St. Louis, MO, USA) density gradient centrifugation. To test the effect of TARC-PE38, these primary cells were incubated in the presence or absence of TARC-PE38, supplemented with $20 \mathrm{U} / \mathrm{ml}$ recombinant human IL2 (Shionogi Pharmaceutical, Osaka, Japan) for 5 days.

All research protocols were approved by the Institutional Review Boards of the National Institute of Infectious Diseases (Tokyo, Japan) before the start of the study.

\section{Mice}

NOD/SCID IL2-receptor- $\gamma$-chain-knockout (NOG) and NOD/SCID Jak3-knockout (NOJ) mice were obtained from the Central Institute for Experimental Animals (Kawasaki, Japan) and Kumamoto University (Kumamoto, Japan), respectively $[60,61]$. These mice were maintained under specific-pathogen-free conditions at the Animal Center of the National Institute of Infectious Diseases. Research protocols for the animal experiments were approved by the Animal Center and the ethics committee at the National Institute of Infectious Diseases, and they were performed according to institutional guidelines for the experimental use of animals.

\section{Production of TARC-fused recombinant proteins}

The generation of TARC-PE38 and TARC-OFA, used as a control, has been described previously [34]. PE38 alone (without TARC) was produced as well.

Because TARC-PE38 has a tag at the $\mathrm{C}$ terminus to purify this protein, we also generated a different form of TARC-PE38, which the same tag is conjugated with at the $\mathrm{N}$ terminus to make the $\mathrm{C}$ terminus ending in REDL(K) or KDEL that is needed for the toxin activity of PE [62, 63]. However, this form was not used in this study, due to its low activity relative to that of TARC-PE38 (data not shown).

\section{Cell viability assay}

Approximately $1 \times 10^{5}$ cells were seeded in each well of a 12-well plate. Different doses $(0-20 \mu \mathrm{g} / \mathrm{ml})$ of TARCPE38 were then added to the wells containing the target cells, in triplicate. As controls, other cells were treated in parallel with the same volume of PBS, the same doses of TARC-OFA, and/or the same doses of PE38 alone.

To determine whether the effect of TARC-PE38 is dependent on furin, a furin inhibitor (Furin Inhibitor I, Calbiochem, Billerica, MA, USA) $(75 \mu \mathrm{M})$ was added to $\mathrm{S} 1 \mathrm{~T}$ cells seeded as described above in the presence or absence of TARC-PE38 (500 ng/ml). As an additional control, TARC-PE38 alone was added to the cells in parallel.

These mixtures were incubated for 4-5 days, and cell viability was quantified daily with the standard Trypanblue exclusion method by counting the number of live cells $\left(\times 10^{5} / \mathrm{ml}\right)$ in each well under a CK40 microscope (Olympus, Tokyo, Japan).

\section{Flow-cytometric analysis}

In preparation for cell-surface staining, aliquots $\left(\sim 5 \times 10^{5}\right)$ of cells were initially incubated with an FcRblocking reagent (Miltenyi Biotec, Gladbach, Germany) at $4{ }^{\circ} \mathrm{C}$ for $15 \mathrm{~min}$. Cell lines were then stained with or without fluorescein isothiocyanate-labeled anti-CCR4 antibody (R\&D Systems, Minneapolis, MN, USA) at $4{ }^{\circ} \mathrm{C}$ for $30 \mathrm{~min}$. PBMCs were incubated with or without fluorescein isothiocyanate-labeled anti-human CD4 antibody, phycoerythrin-labeled anti-human CD25 antibody, and allophycocyanin-labeled anti-human CCR4 or CD45 antibody (eBioscience, San Diego, CA, USA) at $4{ }^{\circ} \mathrm{C}$ for $30 \mathrm{~min}$.

The stained samples were fixed in $4 \%$ paraformaldehyde (Wako, Osaka, Japan) and analyzed with a FACSCalibur flow cytometer using the CellQuest software (BD Pharmingen, Franklin Lakes, NJ, USA).

\section{Quantitation of HTLV-1 proviral load}

To determine the PVL, the copy numbers of proviral DNA were measured with real-time PCR using the 7500 Fast Real-Time PCR System (Applied Biosystems, Foster City, CA, USA). Genomic DNA ( 200 ng) isolated from PBMCs with a QIAamp DNA Blood Mini Kit (Qiagen, Hilden, Germany) was used as the PCR template. Quantitative real-time PCR was performed in duplicate to amplify the $p X$ region of the HTLV-1 provirus. The copy numbers of the human RNase $P$ gene were measured in parallel as an internal control. The primers and 
probe for RNase $P$ were purchased from Applied Biosystems. Those for HTLV-1 $p X$ were: forward primer pX2-S (5'-CGGATACCCAGTCTACGTGTT-3'), reverse primer pX2-AS (5'-CAGTAGGGCGTGACGATGTA-3'), and FAM-labeled pX2 probe (5'-CTGTGTACAAGGC GACTGGTGCC-3') [64]. The copy number of $p X$ in each sample was determined relative to that in TL-Om1 cells. Finally, the PVLs of the tested cells were calculated as $([2 \times$ copies of $p X] /[$ copies of RNase P] $) \times 100$ and expressed as copies $/ 100$ cells.

\section{Quantitation of furin expression}

Quantitative real-time reverse transcription (RT)-PCR with the same system as described above was used to determine the mRNA levels of furin, in various cells. After JEX22 cells were stimulated for $16 \mathrm{~h}$, tdTomato-positive cells were sorted with JSAN (Bay Bioscience, Kobe, Japan) and used. After total RNA was isolated from the cells and purified with Isogen (Wako, Osaka, Japan), quantitative real-time RT-PCR was performed, in duplicate, to quantify both FURIN and GAPDH (internal control). The primer set for the FURIN was: forward primer $5^{\prime}$-TTCAC CAACACGTGGGCTG-3' and reverse primer $5^{\prime}$-CGAT GCCAGAAGTGGTAATAGTCC-3'. The primer set for GAPDH was: forward primer 5'-ACCCACTCCTCCAC CTTTGA- $3^{\prime}$ and reverse primer $5^{\prime}$-CTGTTGCTGTAGC CAAATTCGTT- $3^{\prime}$. The furin mRNA level in each sample was calculated as $2^{-(\mathrm{Ct}[\mathrm{furin}]-\mathrm{Ct}[\mathrm{GAPDH}])}$ and expressed as the fold difference relative to that in Jurkat cells.

\section{Administration of TARC-PE38 to a tumor-bearing mouse model}

Ten NOG mice were anesthetized with pentobarbital sodium (Kyoritsuseiyaku, Tokyo, Japan) and the postauricular region of each mouse was inoculated subcutaneously with $2 \times 10^{7}$ HUT-102 cells [39]. After the cells were grown for $\sim 24 \mathrm{~h}$, either $25 \mu \mathrm{g}$ of TARC-PE38 per mouse or the same volume of PBS (control) was administered to the same region in five mice per group daily for 5 days. All the mice were sacrificed 2 weeks after inoculation with the cells and the subcutaneous tumors were excised, weighed, and photographed with a standard digital camera (Fujifilm, Tokyo, Japan).

\section{Establishment of humanized mice}

Mononuclear cells were isolated from human cord blood (provided by Tokyo Cord Blood Bank, Tokyo, Japan) with Ficoll-Histopaque density gradient centrifugation. Human CD34 ${ }^{+}$hematopoietic stem cells (HSCs) were then purified with a Magnetic-Activated Cell Sorting Direct CD34 Progenitor Cell Isolation Kit (Miltenyi Biotec), according to the manufacturer's instructions. After the cells were enriched twice, more than $85 \%$ of the HSCs obtained were CD34 $4^{+}$. These cells $\left(1-2 \times 10^{5}\right.$ cells per mouse) were immediately transplanted intrahepatically into newborn NOJ mice [61]. At about 3 months after transplantation, the frequency of human $\mathrm{T}$ cells in PBMCs was checked with flow cytometry to determine whether the mice were humanized.

\section{Administration of TARC-PE38 to HTLV-1-infected humanized mice}

Approximately $2 \times 10^{7}$ MT-2 cells were treated with $50 \mathrm{\mu g} / \mathrm{ml}$ MMC (Sigma-Aldrich) at $37^{\circ} \mathrm{C}$ for $1 \mathrm{~h}$. Six humanized mice were then inoculated intraperitoneally with $\sim 2.5 \times 10^{6}$ MMC-treated cells per mouse and three control humanized mice were not inoculated. After 2 weeks, either $10 \mu \mathrm{g}$ of TARC-PE38 per mouse or the same volume of PBS (control) was administered intravenously every day for 4 days into three mice per group inoculated with MT-2 cells, and three control mice were untreated. PBMCs were isolated from all nine mice on days 0 (the day of inoculation with MT-2 cells), 14, 21, 28, and later. The frequency of HTLV-1-infected cells and their PVLs were then tested with flow cytometry and quantitative PCR, respectively.

\section{Statistical analysis}

The data were expressed as means \pm standard deviations (SD) for statistical analysis. Differences between groups were determined with Student's $t$ test. The correlation coefficient, R, was calculated with Spearman's rank correlation test to examine the correlation between two parameters. $\mathrm{P}<0.05$ was considered significant. These analyses were performed using GraphPad Prism (GraphPad Software, La Jolla, CA, USA).

\section{Additional files}

\footnotetext{
Additional file 1: Figure S1. Viability of MT-2 cells treated with MMC. After MT-2 cells were treated with $50 \mu \mathrm{g} / \mathrm{ml} \mathrm{MMC,} \mathrm{they} \mathrm{were} \mathrm{cultured}$ in vitro and the number of live cells was counted daily with the standard Trypan-blue exclusion method to check the viability of MT-2 cells. At three days post-MMC treatment most of the cells were dead.
}

Additional file 2: Figure S2. Phenotype of MT-2 cells. Expression of the indicated molecules on MT-2 cells was analyzed by flow cytometry. This analysis showed that MT-2 cells are $\mathrm{CD} 45^{-} \mathrm{CD} 3^{-} \mathrm{CD} 4^{+} \mathrm{CD} 8^{-}$. This phenotype of cells was analyzed similarly in samples from humanized mice inoculated with MT-2 cells and data obtained are shown in Additional file 3: Table S1.

Additional file 3: Table S1. Detection of MT-2 cells in humanized mice at 2 weeks post-inoculation with non- or MMC-treated MT-2 cells. Frequencies of MT-2 cells and HTLV-1 PVLs were tested with flow cytometry and quantitative PCR, respectively, in splenocytes and PBMCs obtained from humanized mice at 2 weeks post-inoculation with non- or MMCtreated MT-2 cells. In either mouse group MT-2 cells were not detected by flow cytometry (see Additional file 2: Figure S2 also). While the provirus was detected in splenocytes alone obtained from mice inoculated with non-treated MT-2 cells, it was not at all in splenocytes and PBMCs obtained from mice inoculated with MMC-treated MT-2 cells. 
Additional file 4: Figure S3. Therapeutic effects of TARC-PE38 on $\mathrm{CD}^{+}{ }^{+} \mathrm{CCR} 4^{+}$cells in HTLV-1-infected humanized mice. To assess the therapeutic effect of TARC-PE38 on HTLV-1-infected cells, peripheral blood was obtained from all the mice. The PBMCs were isolated and the frequency of human $\mathrm{CD} 4^{+} \mathrm{CCR} 4^{+}$cells was determined with flow cytometry. The data are representative of each group as follows: none, uninfected untreated mice; MT-2 + PBS, HTLV-1-infected mice treated with PBS; MT-2 + TARC-PE38, HTLV-1-infected mice treated with TARC-PE38. The number indicated in the upper right quadrant is the frequency of human $\mathrm{CD}^{+}{ }^{\mathrm{CCCR}} 4^{+}$cells $(\%)$.

Additional file 5: Table S2. Characteristics of HTLV-1-infected individuals from which blood samples were collected to test a correlation between PVLs and expression of furin.

Additional file 6: Figure S4. Independence of furin expression from induced expression of HTLV-1 Tax. Although expression of Tax was definitely induced by adding $\mathrm{Cd}^{2+}$ to JPX-9 cells (lower panel), expression of furin was not increased as compared with that before adding it (upper panel).

\section{Abbreviations}

ADCC: antibody-dependent cellular cytotoxicity; ATL: adult T-cell leukemia; CCR4: CC chemokine receptor 4; FCR: Fc receptor; HAM/TSP: HTLV-1-associated myelopathy/tropical spastic paraparesis; HSCs: hematopoietic stem cells; HTLV-1: human T-cell leukemia virus type 1; IL2: interleukin 2; JSPFAD: Joint Study on Predisposing Factors of ATL Development; mAb: monoclonal antibody; MDC: macrophage-derived chemokine; MFI: mean fluorescence intensity; MMC: mitomycin C; NOG: NOD/SCID IL2-receptor- $\gamma$-chain-knockout; NOJ: NOD/SCID Jak3-knockout; PBMCs: peripheral blood mononuclear cells; PBS: phosphate-buffered saline; PE: Pseudomonas exotoxin; PMA: phorbol 12-myristate 13-acetate; PVL: proviral load; RT: reverse transcription; SD: standard deviations; TARC: thymus and activation-regulated chemokine; TARCOFA: TARC-fused oncofetal antigen; TARC-PE38: TARC-fused truncated 38-kDa Pseudomonas exotoxin; Tregs: regulatory T cells.

\section{Authors' contributions}

$\mathrm{MH}$ and $\mathrm{KO}$ designed and performed the experiments, analyzed the results, and wrote the manuscript. ST, KT, MS, MK, and KA performed the experiments. $\mathrm{KM}$ provided materials. $\mathrm{SO}$ supported the animal experiments. NY, $\mathrm{AB}, \mathrm{KY}$, and IH discussed the results. All authors read and approved the final manuscript.

\section{Author details}

1 Department of Safety Research on Blood and Biological Products, National Institute of Infectious Diseases, Musashimurayama, Tokyo 208-0011, Japan. ${ }^{2}$ Medical Facilities Support Department, Micron Inc., Chiyoda-ku, Tokyo 100-0005, Japan. ${ }^{3}$ Division of Tumor and Cellular Biochemistry, Department of Medical Sciences, Faculty of Medicine, University of Miyazaki, Kiyotake, Miyazaki 889-1692, Japan. ${ }^{4}$ Division of Hematopoiesis, Center for AIDS Research, Kumamoto University, Kumamoto 860-0811, Japan. ${ }^{5}$ Department of Microbiology, Yong Loo Lin School of Medicine, National University of Singapore, Singapore 117599, Singapore. ${ }^{6}$ Immunoregulation Section, Laboratory of Molecular Biology and Immunology, National Institute on Aging, Baltimore, MD 21224, USA.

\section{Acknowledgements}

The authors thank N. Arima for providing the S1T cells, K. Sugamura for providing the TL-Om1 and JPX-9 cells, J. Fujisawa for providing the JET35 and JEX22 cells, and K. Hirose for helpful discussions. We also acknowledge the technical support by Y. Takahama and Y. Hamaguchi. This work was supported by a Health Labour Sciences Research Grant from the Ministry of Health, Labour and Welfare of Japan (Grant number H23-sinkou-ippan-016 to $\mathrm{HH}$ ) Research Program on Emerging and Re-emerging Infectious Diseases from Japan Agency for Medical Research and Development, AMED to IH, and the Japanese Society for the Promotion of Science (JSPS) KAKENHI (grant number 24591414, 15K09462 to IH, and 15K08439 to KO).

\section{Compliance with ethical guidelines}

\section{Competing interests}

The authors declare that they have no competing interests.

Received: 29 March 2015 Accepted: 12 August 2015

Published online: 20 August 2015

\section{References}

1. Uchiyama T, Yodoi J, Sagawa K, Takatsuki K, Uchino H. Adult T-cell leukemia: clinical and hematologic features of 16 cases. Blood. 1977;50:481-92.

2. Yoshida M, Miyoshi I, Hinuma Y. Isolation and characterization of retrovirus from cell lines of human adult T-cell leukemia and its implication in the disease. Proc Natl Acad Sci USA. 1982;79(6):2031-5.

3. Osame M, Usuku K, Izumo S, ljichi N, Amitani H, Igata A, et al. HTLV-I associated myelopathy, a new clinical entity. Lancet. 1986;1(8488):1031-2.

4. Gessain A, Barin F, Vernant JC, Gout O, Maurs L, Calender A, et al. Antibodies to human T-lymphotropic virus type-I in patients with tropical spastic paraparesis. Lancet. 1985;2(8452):407-10.

5. Mochizuki M, Watanabe T, Yamaguchi K, Takatsuki K, Yoshimura K, Shirao $M$, et al. HTLV-I uveitis: a distinct clinical entity caused by HTLV-I. Jpn J Cancer Res. 1992;83(3):236-9.

6. Iwanaga M, Watanabe T, Yamaguchi K. Adult T-cell leukemia: a review of epidemiological evidence. Front Microbiol. 2012;3:322.

7. Satake M, Yamaguchi K, Tadokoro K. Current prevalence of HTLV-1 in Japan as determined by screening of blood donors. J Med Virol. 2012;84(2):327-35.

8. Bazarbachi A, Plumelle Y, Carlos Ramos J, Tortevoye P, Otrock Z, Taylor G, et al. Meta-analysis on the use of zidovudine and interferon-alfa in adult T-cell leukemia/lymphoma showing improved survival in the leukemic subtypes. J Clin Oncol. 2010;28(27):4177-83.

9. Kchour G, Rezaee R, Farid R, Ghantous A, Rafatpanah H, Tarhini M, et al The combination of arsenic, interferon-alpha, and zidovudine restores an "immunocompetent-like" cytokine expression profile in patients with adult T-cell leukemia lymphoma. Retrovirology. 2013;10:91.

10. Yamaguchi K, Watanabe T. Human T lymphotropic virus type-I and adult T-cell leukemia in Japan. Int J Hematol. 2002;76(Suppl 2):240-5.

11. Marçais A, Suarez F, Sibon D, Frenzel L, Hermine O, Bazarbachi A. Therapeutic options for adult T-cell leukemia/lymphoma. Curr Oncol Rep. 2013;15(5):457-64.

12. Yamaguchi K, Uozumi K, Taguchi H, et al. Nationwide Cohort Study of HTLV-1 Carriers in Japan: Joint Study on Predisposing Factors of ATL Development (JSPFAD) [abstract]. AIDS Res Hum Retroviruses. 2007;23(4):581-600 (Abstract 0-23).

13. Iwanaga M, Watanabe T, Utsunomiya A, Okayama A, Uchimaru K, Koh KR, et al. Human T-cell leukemia virus type I (HTLV-1) proviral load and disease progression in asymptomatic HTLV-1 carriers: a nationwide prospective study in Japan. Blood. 2010;116(8):1211-9.

14. Imai T, Baba M, Nishimura M, Kakizaki M, Takagi S, Yoshie O. The T celldirected CC chemokine TARC is a highly specific biological ligand for CC chemokine receptor 4. J Biol Chem. 1997;272(23):15036-42.

15. Imai T, Chantry D, Raport CJ, Wood CL, Nishimura M, Godiska R, et al. Macrophage-derived chemokine is a functional ligand for the CC chemokine receptor 4. J Biol Chem. 1998;273(3):1764-8.

16. Imai T, Nagira M, Takagi S, Kakizaki M, Nishimura M, Wang J, et al. Selective recruitment of CCR4-bearing Th2 cells toward antigen-presenting cells by the CC chemokines thymus and activation-regulated chemokine and macrophage-derived chemokine. Int Immunol. 1999;11(1):81-8.

17. Hirahara K, Liu L, Clark RA, Yamanaka K, Fuhlbrigge RC, Kupper TS. The majority of human peripheral blood $\mathrm{CD} 4^{+} \mathrm{CD} 25^{\text {high }} \mathrm{Foxp} 3^{+}$ regulatory $T$ cells bear functional skin-homing receptors. J Immunol. 2006;177(7):4488-94.

18. Yoshie O, Fujisawa R, Nakayama T, Harasawa H, Tago H, Izawa D, et al. Frequent expression of CCR4 in adult T-cell leukemia and human T-cell leukemia virus type 1-transformed T cells. Blood. 2002;99(5):1505-11. 
19. Ishida T, Utsunomiya A, lida S, Inagaki H, Takatsuka Y, Kusumoto S, et al Clinical significance of CCR4 expression in adult T-cell leukemia/lymphoma: its close association with skin involvement and unfavorable outcome. Clin Cancer Res. 2003;9(10 Pt 1):3625-34.

20. Yamano Y, Araya N, Sato T, Utsunomiya A, Azakami K, Hasegawa D, et al. Abnormally high levels of virus-infected IFN- $\gamma^{+} \mathrm{CCR} 4^{+} \mathrm{CD} 4^{+} \mathrm{CD} 25^{+} \mathrm{T}$ cells in a retrovirus-associated neuroinflammatory disorder. PLoS One. 2009;4(8):e6517.

21. Araya N, Sato T, Ando H, Tomaru U, Yoshida M, Coler-Reilly A, et al. HTLV-1 induces a Th1-like state in $\mathrm{CD}^{+}{ }^{+} \mathrm{CCR} 4^{+} \mathrm{T}$ cells. J Clin Invest. 2014;124(8):3431-42.

22. Hieshima K, Nagakubo D, Nakayama T, Shirakawa AK, Jin Z, Yoshie O. Tax-inducible production of CC chemokine ligand 22 by human $T$ cell leukemia virus type 1 (HTLV-1)-infected T cells promotes preferential transmission of HTLV-1 to CCR4-expressing CD4 ${ }^{+}$T cells. J Immunol. 2008;180(2):931-9.

23. Okuma K, Nakamura M, Nakano S, Niho Y, Matsuura Y. Host range of human T-cell leukemia virus type I analyzed by a cell fusion-dependent reporter gene activation assay. Virology. 1999;254(2):235-44.

24. Toulza F, Nosaka K, Tanaka Y, Schioppa T, Balkwill F, Taylor GP, et al. Human T-lymphotropic virus type 1 -induced CC chemokine ligand 22 maintains a high frequency of functional FoxP3 ${ }^{+}$regulatory T cells. J Immunol. 2010;185(1):183-9.

25. Niwa R, Shoji-Hosaka E, Sakurada M, Shinkawa T, Uchida K, Nakamura $\mathrm{K}$, et al. Defucosylated chimeric anti-CC chemokine receptor $4 \lg \mathrm{G} 1$ with enhanced antibody-dependent cellular cytotoxicity shows potent therapeutic activity to T-cell leukemia and lymphoma. Cancer Res. 2004;64(6):2127-33.

26. Ishida T, lida S, Akatsuka Y, Ishii T, Miyazaki M, Komatsu H, et al. The CC chemokine receptor 4 as a novel specific molecular target for immunotherapy in adult T-Cell leukemia/lymphoma. Clin Cancer Res. 2004;10(22):7529-39.

27. Ito A, Ishida T, Utsunomiya A, Sato F, Mori F, Yano H, et al. Defucosylated anti-CCR4 monoclonal antibody exerts potent ADCC against primary ATLL cells mediated by autologous human immune cells in NOD/Shiscid, IL-2R $\gamma^{\text {null }}$ mice in vivo. J Immunol. 2009;183(7):4782-91.

28. Ishii T, Ishida T, Utsunomiya A, Inagaki A, Yano H, Komatsu H, et al. Defucosylated humanized anti-CCR4 monoclonal antibody KW-0761 as a novel immunotherapeutic agent for adult T-cell leukemia/lymphoma. Clin Cancer Res. 2010;16(5):1520-31.

29. Yamamoto K, Utsunomiya A, Tobinai K, Tsukasaki K, Uike N, Uozumi K, et al. Phase I study of KW-0761, a defucosylated humanized anti-CCR4 antibody, in relapsed patients with adult T-cell leukemia-lymphoma and peripheral T-cell lymphoma. J Clin Oncol. 2010;28(9):1591-8.

30. Ishida T, Joh T, Uike N, Yamamoto K, Utsunomiya A, Yoshida S, et al. Defucosylated anti-CCR4 monoclonal antibody (KW-0761) for relapsed adult T-cell leukemia-lymphoma: a multicenter phase II study. J Clin Oncol. 2012;30(8):837-42.

31. Ishida T, Ito A, Sato F, Kusumoto S, lida S, Inagaki H, et al. Stevens-Johnson Syndrome associated with mogamulizumab treatment of adult T-cell leukemia/lymphoma. Cancer Sci. 2013;104(5):647-50.

32. Yonekura K, Kanzaki T, Gunshin K, Kawakami N, Takatsuka Y, Nakano N, et al. Effect of anti-CCR4 monoclonal antibody (mogamulizumab) on adult T-cell leukemia-lymphoma: cutaneous adverse reactions may predict the prognosis. J Dermatol. 2014;41(3):239-44.

33. Nakano N, Kusumoto S, Tanaka Y, Ishida T, Takeuchi S, Takatsuka Y, et al. Reactivation of hepatitis B virus in a patient with adult T-cell leukemialymphoma receiving the anti-CC chemokine receptor 4 antibody mogamulizumab. Hepatol Res. 2014;44(3):354-7.

34. Baatar D, Olkhanud P, Newton D, Sumitomo K, Biragyn A. CCR4-expressing T cell tumors can be specifically controlled via delivery of toxins to chemokine receptors. J Immunol. 2007;179(3):1996-2004

35. Inocencio NM, Moehring JM, Moehring TJ. Furin activates Pseudomonas exotoxin A by specific cleavage in vivo and in vitro. J Biol Chem. 1994;269(50):31831-5

36. Ornatowski W, Poschet JF, Perkett E, Taylor-Cousar JL, Deretic V. Elevated furin levels in human cystic fibrosis cells result in hypersusceptibility to exotoxin A-induced cytotoxicity. J Clin Invest. 2007;117(11):3489-97.

37. Willnow TE, Herz J. Genetic deficiency in low density lipoprotein receptorrelated protein confers cellular resistance to Pseudomonas exotoxin
A. Evidence that this protein is required for uptake and degradation of multiple ligands. J Cell Sci. 1994;107(Pt 3):719-26.

38. Mucci D, Forristal J, Strickland D, Morris R, Fitzgerald D, Saelinger CB. Level of receptor-associated protein moderates cellular susceptibility to pseudomonas exotoxin A. Infect Immun. 1995;63(8):2912-8.

39. Dewan MZ, Terashima K, Taruishi M, Hasegawa H, Ito M, Tanaka Y, et al. Rapid tumor formation of human T-cell leukemia virus type 1-infected cell lines in novel NOD-SCID/ $\gamma c^{\text {null }}$ mice: suppression by an inhibitor against NF-кB. J Virol. 2003;77(9):5286-94.

40. de Lavareille A, Roufosse F, Schandené L, Stordeur P, Cogan E, Goldman M. Clonal Th2 cells associated with chronic hypereosinophilia: TARC-induced CCR4 down-regulation in vivo. Eur J Immunol. 2001;31(4):1037-46

41. Chaudhary VK, Mizukami T, Fuerst TR, FitzGerald DJ, Moss B, Pastan I, et al. Selective killing of HIV-infected cells by recombinant human CD4-Pseudomonas exotoxin hybrid protein. Nature. 1988;335(6188):369-72.

42. Chowdhury PS, Viner JL, Beers R, Pastan I. Isolation of a high-affinity stable single-chain Fv specific for mesothelin from DNA-immunized mice by phage display and construction of a recombinant immunotoxin with anti-tumor activity. Proc Natl Acad Sci USA. 1998;95(2):669-74.

43. Weldon JE, Pastan I. A guide to taming a toxin: recombinant immunotoxins constructed from Pseudomonas exotoxin A for the treatment of cancer. FEBS J. 2011;278(23):4683-700.

44. Kreitman RJ, Wilson WH, White JD, Stetler-Stevenson M, Jaffe ES, Giardina $\mathrm{S}$, et al. Phase I trial of recombinant immunotoxin anti-Tac(Fv)-PE38 (LMB-2) in patients with hematologic malignancies. J Clin Oncol. 2000;18(8):1622-36.

45. FitzGerald DJ, Wayne AS, Kreitman RJ, Pastan I. Treatment of hematologic malignancies with immunotoxins and antibody-drug conjugates. Cancer Res. 2011;71(20):6300-9.

46. Mellor JD, Brown MP, Irving HR, Zalcberg JR, Dobrovic A. A critical review of the role of Fc gamma receptor polymorphisms in the response to monoclonal antibodies in cancer. J Hematol Oncol. 2013;6:1.

47. Nagelkerke SQ, Kuijpers TW. Immunomodulation by IVIg and the role of Fc-Gamma receptors: classic mechanisms of action after all? Front Immunol. 2015;5:674.

48. Mazor R, Eberle JA, Hu X, Vassall AN, Onda M, Beers R, et al. Recombinant immunotoxin for cancer treatment with low immunogenicity by identification and silencing of human T-cell epitopes. Proc Natl Acad Sci USA. 2014;111(23):8571-6.

49. Pesu M, Watford WT, Wei L, Xu L, Fuss I, Strober W, et al. T-cell-expressed proprotein convertase furin is essential for maintenance of peripheral immune tolerance. Nature. 2008:455(7210):246-50.

50. Nagata K, Ohtani K, Nakamura M, Sugamura K. Activation of endogenous c-fos proto-oncogene expression by human T-cell leukemia virus type I-encoded p40tax protein in the human T-cell line Jurkat. J Virol. 1989;63(8):3220-6.

51. Chen Y, Xie X, Gu L, Huang XH, Peng XM. Furin mRNA expression in peripheral blood correlates with chronic hepatitis $B$ virus infection. Hepatol Res. 2013;43(2):208-16.

52. Delamarre L, Rosenberg AR, Pique C, Pham D, Callebaut I, Dokhélar MC. The HTLV-I envelope glycoproteins: structure and functions. J Acquir Immune Defic Syndr Hum Retrovirol. 1996;13(Suppl 1):S85-91.

53. Okuma K, Matsuura Y, Tatsuo H, Inagaki Y, Nakamura M, Yamamoto N, et al. Analysis of the molecules involved in human T-cell leukaemia virus type 1 entry by a vesicular stomatitis virus pseudotype bearing its envelope glycoproteins. J Gen Virol. 2001;82(Pt 4):821-30.

54. Okuma K, Dalton KP, Buonocore L, Ramsburg E, Rose JK. Development of a novel surrogate virus for human T-cell leukemia virus type 1: inhibition of infection by osteoprotegerin. J Virol. 2003;77(15):8562-9.

55. Maeda M, Arima N, Daitoku Y, Kashihara M, Okamoto H, Uchiyama T, et al. Evidence for the interleukin-2 dependent expansion of leukemic cells in adult T cell leukemia. Blood. 1987;70(5):1407-11.

56. Sugamura K, Fujii M, Kannagi M, Sakitani M, Takeuchi M, Hinuma Y. Cell surface phenotypes and expression of viral antigens of various human cell lines carrying human T-cell leukemia virus. Int J Cancer. 1984;34(2):221-8.

57. Miyoshi I, Kubonishi I, Yoshimoto S, Akagi T, Ohtsuki Y, Shiraishi Y, et al. Type $C$ virus particles in a cord T-cell line derived by co-cultivating normal human cord leukocytes and human leukaemic T cells. Nature. 1981;294(5843):770-1. 
58. Gazdar AF, Carney DN, Bunn PA, Russell EK, Jaffe ES, Schechter GP, et al. Mitogen requirements for the in vitro propagation of cutaneous T-cell lymphomas. Blood. 1980;55(3):409-17.

59. Ikebe E, Kawaguchi A, Tezuka K, Taguchi S, Hirose S, Matsumoto T, et al. Oral administration of an HSP90 inhibitor, 17-DMAG, intervenes tumorcell infiltration into multiple organs and improves survival period for ATL model mice. Blood Cancer J. 2013;3:e132.

60. Ito M, Hiramatsu H, Kobayashi K, Suzue K, Kawahata M, Hioki K, et al. $\mathrm{NOD} / \mathrm{SCID} / \gamma_{c}^{\text {null }}$ mouse: an excellent recipient mouse model for engraftment of human cells. Blood. 2002;100(9):3175-82.

61. Okada S, Harada H, Ito T, Saito T, Suzu S. Early development of human hematopoietic and acquired immune systems in new born NOD/Scid/ Jak3 ${ }^{\text {null }}$ mice intrahepatic engrafted with cord blood-derived $\mathrm{CD}_{3}{ }^{+}$cells. Int J Hematol. 2008;88(5):476-82.
62. Chaudhary VK, Jinno Y, FitzGerald D, Pastan I. Pseudomonas exotoxin contains a specific sequence at the carboxyl terminus that is required for cytotoxicity. Proc Natl Acad Sci USA. 1990;87(1):308-12.

63. Seetharam S, Chaudhary VK, FitzGerald D, Pastan I. Increased cytotoxic activity of Pseudomonas exotoxin and two chimeric toxins ending in KDEL. J Biol Chem. 1991;266(26):17376-81.

64. Watanabe M, Ohsugi T, Shoda M, Ishida T, Aizawa S, Maruyama-Nagai M, et al. Dual targeting of transformed and untransformed HTLV-1-infected T cells by DHMEQ, a potent and selective inhibitor of NF- $\mathrm{B}$, as a strategy for chemoprevention and therapy of adult T-cell leukemia. Blood. 2005;106(7):2462-71.

\section{Submit your next manuscript to BioMed Central} and take full advantage of:

- Convenient online submission

- Thorough peer review

- No space constraints or color figure charges

- Immediate publication on acceptance

- Inclusion in PubMed, CAS, Scopus and Google Scholar

- Research which is freely available for redistribution

Submit your manuscript at

www.biomedcentral.com/submit

C Biomed Central 